\title{
Treatment of Metastatic Castration-resistant Prostate Cancer Patients With Abiraterone Acetate and Prednisone and Corresponding Survival Prognostic Factors
}

\author{
MIGUEL E. JIMENEZ ROMERO ${ }^{1}$, MARIA CAMACHO GALLEGO ${ }^{1}$, JOSE C. NAVARRO SERRATO ${ }^{1}$, \\ MIGUEL A. SANCHEZ HURTADO ${ }^{2}$ and JOSE D. SANTOTORIBIO ${ }^{3}$ \\ ${ }^{1}$ Department of Urology, Puerto Real University Hospital, Cadiz, Spain; \\ ${ }^{2}$ Independent Researcher, Cáceres, Spain; \\ ${ }^{3}$ Department of Laboratory Medicine, Puerto Real University Hospital, Cadiz, Spain
}

\begin{abstract}
Background/Aim: The aim of the study was to evaluate the combined treatment with abiraterone acetate and prednisone $(A A+P)$ in patients with castrationresistant prostate cancer $(m C P R C)$, and to identify the survival prognostic factors. Patients and Methods: Patients diagnosed with $m C P R C$ not previously treated with chemotherapy and administered with $A A+P$ were classified into two groups: those with lower and higher survival rates (at 30 months vs. 60 months). Results: A total of 53 patients were studied at the time of $m C R P C$ diagnosis. Patients with the highest survival rate had suffered prostate cancer for $>45$ months. At the time of initial prostate cancer diagnosis, they belonged to the risk groups 1-4, had pain intensity measured according to the brief pain inventory (BPI) scale of 0-2, were treated with $A A+P>16$ months, and had the following tumour marker serum levels: $L D H$ baseline $\leq 163 \mathrm{U} / \mathrm{l}$, alkaline phosphatase at 6 months $\leq 56 \mathrm{U} / \mathrm{l}$ and PSA at 6 months $\leq 0.95 \mathrm{ng} / \mathrm{ml}$. Conclusion: Good response to treatment with $A A+P$ for patients with $m C R P C$ was demonstrated. Factors that contributed to the higher prognostic accuracy were time suffering from prostate cancer, the intensity of the pain measured by the BPI scale, the duration of $A A+P$ treatment, and tumour marker levels.
\end{abstract}

This article is freely accessible online.

Correspondence to: Dr. Miguel Efrén Jiménez Romero, Department of Urology, Puerto Real University Hospital, Carretera Nacional IV - Km. 665, 11510 - Puerto Real (Cadiz), Spain. Tel: +34 956005000, Fax: +34 956005658, e-mail: miguelefrenjimenez@gmail.com

Key Words: Prostate cancer, castration-resistant, abiraterone acetate, prednisone, chemo-naïve, survival, prognostic models.
Despite the efforts made for the early detection of prostate cancer (PC) and the aggressive treatments used, some patients often suffer metastasis (in $90 \%$ of cases, in fact). Androgen deprivation therapy (ADT) is the fundamental basis for the treatment of metastatic prostate cancer patients (1). Although most patients show an excellent initial response to hormone deprivation, variable times have been observed regarding progression to the castration-resistant phase. This response is the result of tumour resistance to ADT. Its clinical manifestation is seen as a radiological or biochemical progression, showing testosterone levels after castration. Castration-resistant prostate cancer (mCRPC) is often associated with a poor prognosis and low survival rates (2). However, the availability of oral hormone therapies that target the androgen receptors that have shown significant benefits in terms of the overall survival rate and quality of life (3-5), stresses the importance of monitoring progression. All of these elements pose a challenge when choosing the type of treatment, optimal treatment ending time and subsequent treatments. Thus, it is fundamental to choose the therapeutic strategies that are beneficial for the patients.

Many authors have studied known specific prognostic factors for overall survival rates and radiological progression-free survival (rPFS), in order to be able to foresee the condition's progression $(6,7)$. Their aim is to predict response to treatment, so as to identify and profile patient subgroups that differ in terms of progression, allowing determination of the sequence of treatments or perhaps the administration of combination therapies for improving patient survival time and quality of life (8). Different prognostic models have been generated and published $(9,10)$, which consider multiple combinations of variables. Nonetheless, within the reality of clinical practices, the majority of the models have limited benefits, since their validation, flexibility and interpretation are still not clear. 
This study analyses the prognostic factors of overall survival rates in patients suffering from mCRPC who have been treated with abiraterone. The possibility that some of the analysed variables may be used to identify patient subgroups with a higher survival rate was also studied. Additionally, patient sub-groups were analysed based on baseline characteristics, in an effort to explore more in-depth the potential role that clinical parameters may play in predicting treatment response in those patients.

\section{Patients and Methods}

Design. A retrospective, descriptive and cross-sectional study carried out at the University Hospital of Puerto Real (Cadiz, Spain). The Helsinki Declaration's (Fortaleza, 2013) ethical recommendations were followed. The methodology of this study was approved by the Cadiz Research Ethics Committee, and all participants had signed the informed consent form granting permission for their medical history data to be used for biomedical research purposes.

Patients. From February 2013 to June 2019, the medical histories of patients treated at the University Hospital of Puerto Real were analysed to ascertain whether they fitted all the inclusion and none of the exclusion criteria. The inclusion criteria were: male Caucasian patients of any age, diagnosed with mCRPC and treated with AA+P (biochemical and/or radiological diagnosis). The exclusion criteria were: living patients with a follow-up time under two years, and patients lacking data regarding any variables to be studied.

The patients were divided into two groups, bearing in mind their survival time from the start of $\mathrm{AA}+\mathrm{P}$ treatment: patients with longer survival (group A), and patients with shorter survival (group B). The survival mean of the population studied was used as the discriminatory value to classify patients within one of these groups.

Variables. Dependent variable: Qualitative dichotomous analysis of the data regarding patients with longer or shorter survival rates since the start of $\mathrm{AA}+\mathrm{P}$ treatment. Categorisation of group A: patients with higher survival rate (longer than average), and group $B$ : patients with shorter survival rate (shorter than average).

Baseline independent variables: Variables determined before beginning $\mathrm{AA}+\mathrm{P}$ treatment.

A) Qualitative baseline:

1. Risk group [1-5]: the risk group to which the patient belonged when diagnosed with prostate cancer (PC). 1: Low risk PC, localised stage; 2: Intermediate risk PC, localised stage; 3: High risk PC, localised stage; 4: Advanced localised PC (extracapsular damage observed, seminal vesicles or adjacent structures invaded (T3-T4) or metastasis found on regional nodes $(\mathrm{N}+)$; 5: Metastatic $\mathrm{PC}$ at the time of diagnosis.

2. Gleason-ISUP [1-5]: classification according to the GleasonISUP grade resulting from the prostate biopsy at the time of diagnosis. The higher the ISUP, the more aggressive the neoplastic process. 1: ISUP 1: Gleason 6 or lower; 2: ISUP 2: Gleason $7(3+4)$; 3: ISUP 3: Gleason 7 (4+3); 4: ISUP 4: Gleason 8. ISUP; 5: Gleason 9 or 10.

3. Previous treatment [1-4]: the initial treatment received by the patient after PC diagnosis, before developing CRPC and being treated with AA+P. 1: surgery; 2: radiotherapy (RT); 3: RT+androgen deprivation therapy (ADT); 4: only ADT.
4. ECOG [0-5]: patient performance capacity according to the ECOG scale (Eastern Cooperative Oncology Group) at the start of treatment with $\mathrm{AA}+\mathrm{P}$. The scale presents six levels of performance, ranging from normality (ECOG 0 ) to death (ECOG 5).

5. Brief pain inventory [BPI, 0-7]: pain intensity and how it interferes with daily activities, measured through the BPI questionnaire, and filled out by the patient before treatment with $\mathrm{AA}+\mathrm{P}$.

B) Quantitative baseline:

1. Age (years): the patient's age at the start of treatment with abiraterone.

2. Time suffering from PC (months): the duration from the PC diagnosis to CRPC and start of $\mathrm{AA}+\mathrm{P}$ treatment.

3. Time ADT (months): the duration from the start of ADT to progression to castration-resistant disease and starting $\mathrm{AA}+\mathrm{P}$ treatment.

4. Number of bone lesions (units): the number of bone metastases suffered by the patient at the start of treatment with abiraterone.

5. Prostate-specific antigen (PSA) baseline ( $\mathrm{ng} / \mathrm{ml})$ : PSA baseline measured in the serum at the start of $\mathrm{AA}+\mathrm{P}$ treatment.

6. Alkaline phosphatase (AP) baseline (U/l): AP baseline measured in the serum at the start of $\mathrm{AA}+\mathrm{P}$ treatment.

7. Lactate dehydrogenase (LDH) baseline (U/1): LDH baseline measured in the serum at the start of $\mathrm{AA}+\mathrm{P}$ treatment.

Treatment independent monitoring variables: variables determined during treatment with abiraterone.

A) Qualitative in terms of treatment monitoring:

1. Number of lines of treatment [0-6]: the number of lines of treatment received by the patient once they had been diagnosed with CRPC. 1: $\mathrm{AA}+\mathrm{P}$ as first line of treatment, no subsequent sequencing to another type of treatment; 2 : the patient is given a second line of treatment; 3: the patient is given a third line of treatment; 4 : the patient is given a fourth line of treatment; 5 : the patient is given a fifth line of treatment; 6 : the patient is given a sixth line of treatment.

2. Radiological progression [0-3]: disease progression defined as the progression to the bone and/or soft tissue metastasis according to RECIST after beginning $\mathrm{AA}+\mathrm{P}$ treatment.

0 : absence of progression during the follow-up; 1: bone metastasis progression (at least two new bone metastases are observed); 2: metastatic progression observed in soft tissues; 3 : bone and soft tissue metastatic progression observed.

3. Biochemical progression [0-1]: 50\% PSA increase from nadir reached at the start of $\mathrm{AA}+\mathrm{P}$ treatment. 0 : no; 1 : yes.

4. PSA response [0-1]: decrease of at least $50 \%$ of baseline PSA levels within the first 12 weeks of beginning treatment with $\mathrm{AA}+\mathrm{P}$. 0 : no; 1 : yes.

5. PSA $30 \%$ [0-1]: PSA levels reduction equal to or greater than 30\%. 0: no; 1 : yes.

6. PSA $50 \%$ [0-1]: PSA levels reduction equal to or greater than 50\%. 0: no; 1 : yes.

7. PSA $90 \%$ [0-1]: PSA levels reduction equal to or greater than 90\%. 0: no; 1 : yes.

8. PSA Flare [0-1]: any PSA increase within the first 12 weeks of beginning $\mathrm{AA}+\mathrm{P}$ treatment, followed by a decrease below the initial baseline, is considered to be a PSA flare. 0: no; 1: yes.

B) Quantitative in terms of treatment monitoring:

1. Treatment duration (months): the duration from the begining of $\mathrm{AA}+\mathrm{P}$ treatment until suspention due to disease progression, followed by another form of treatment or patient death. 
Table I. Descriptive statistics of the survival rate of all patients, as well as the groups with higher $(A)$ and lower $(B)$ survival rates.

\begin{tabular}{lccc}
\hline Patients & $\mathrm{n}(\%)$ & Mean survival & Range survival \\
\hline All & $53(100 \%)$ & 24 months & 3-78 months \\
Group A & $27(50.9 \%)$ & 44 months & $24-78$ months \\
Group B & $26(49.1 \%)$ & 14 months & $3-22$ months \\
\hline
\end{tabular}

2. PSA $2 \mathrm{w}, 1 \mathrm{~m}, 2 \mathrm{~m}, 3 \mathrm{~m}, 4 \mathrm{~m}, 5 \mathrm{~m}$ and $6 \mathrm{~m}(\mathrm{ng} / \mathrm{ml})$ : PSA serum levels two weeks after starting AA+P treatment, and monthly until six months.

3. AP $2 \mathrm{w}$, AP $1 \mathrm{~m}, 2 \mathrm{~m}, 3 \mathrm{~m}, 4 \mathrm{~m}, 5 \mathrm{~m}$ and $6 \mathrm{~m}$ (UI/ml): AP serum levels two weeks after starting AA+P treatment, and monthly until six months.

4. LDH $2 \mathrm{w}, 1 \mathrm{~m}, 2 \mathrm{~m}, 3 \mathrm{~m}, 4 \mathrm{~m}, 5 \mathrm{~m}$ and $6 \mathrm{~m}$ (UI/ml): LDH serum levels two weeks after starting AA+P treatment, and monthly until six months.

Data collection. The data was obtained from the patient's medical history. The biochemical markers (PSA, AP and LDH) were determined in peripheral venous blood at the Puerto Real University Hospital Clinical Biochemistry Laboratory according to the following methods. The PSA levels were measured via electrochemiluminescence immunoassays in the Modular Hitachi Cobas E-170 (Roche Diagnostics, Basel, Switzerland) and AP and LDH levels were measured using the enzymatic method in the Modular Hitachi Cobas c-702 (Roche Diagnostics, Basel, Switzerland).

Statistical analysis. The data was processed using the statistical program MEDCALC ${ }^{\circledR} 13.0$ (MedCalc Software, Ostend, Belgium), with a significance level of 0.05 . The quantitative variables underwent the D'Agostino-Pearson test to determine whether or not they had a normal distribution.

For the descriptive analysis, the qualitative variable frequencies, the arithmetic mean and range of the quantitative variables at normal distribution, and the median and range of the quantitative variables at non-Gaussian distribution were used.

The comparison between the two patient groups was carried out using: chi square for the qualitative variables, Student's $t$-test for the quantitative variables at normal distribution, and the nonparametric Mann-Whitney's $U$ test for quantitative variables at nonGaussian distribution.

The area under the receiver-operating characteristic (ROC) curve was used to find the optimal cutoff point for the quantitative variables that showed significant differences within patient groups. In order to reduce the number of false positives, the optimal cut-point value with higher sensitivity, and a specificity higher or equal to $80 \%$ were considered.

The survival analysis was carried out using Kaplan-Meier survival curves, considering the variables that showed significant differences within the groups of patients, thus calculating survival at 60 months from the start of treatment with $\mathrm{AA}+\mathrm{P}$.

\section{Results}

Patients. The medical histories of 61 patients were analysed. Fifty-three patients complied with all the inclusion criteria and

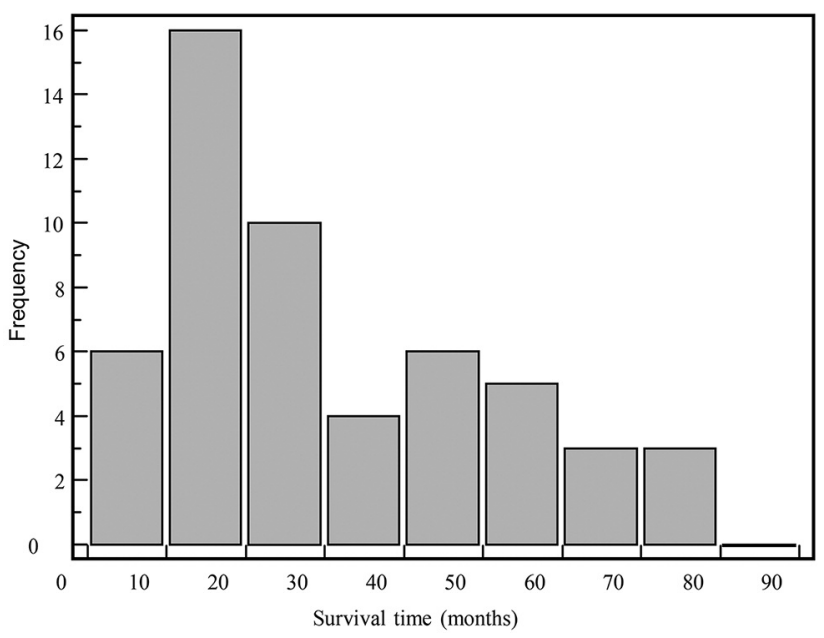

Figure 1. Patients distributed according to survival time.

none of the exclusion criteria. However, eight were excluded from the study (two had no histological confirmation of having prostate adenocarcinoma, and six had begun treatment with a drug that was not $\mathrm{AA}+\mathrm{P}$. The 53 selected patients at the time of diagnosis of mCRPC were between the ages of 47 and 88 years (mean=75). When this study was carried out, 37 of the patients had died $(69.8 \%)$ and 16 were still alive.

The survival ranged from 3 to 78 months, a mean of 24 (confidence interval 95\%=16-35). The patients with a survival rate above or equal to 24 months were classified within the group of longer survival (group A), and patients with a survival rate under 24 months were classified within the group of shorter survival (group B). Twenty-seven patients were included within group A, and 26 within group B.

Descriptive statistics and differences found within the patient groups. Table I and Figure 1 show descriptive statistics regarding the survival rate of patients and their distribution in terms of months of survival up to the starting point of this study. All the quantitative variables presented a non-Gaussian distribution. From the 53 patients with mCRPC, 27 survived beyond 24 months; thus the two-year life expectancy for these patients was $50.9 \%$ (Table I). Almost all patients with mCRPC were above 65 years of age, only three patients presented with this disease in ages below 55 years. Significant differences were not observed in terms of age within patients with longer or shorter survival. Therefore, the age at which $\mathrm{AA}+\mathrm{P}$ treatment was begun was not a prognostic factor. This could be due to the old age of the patients studied.

The descriptive statistics and significant differences between the two patient groups with baseline variables are shown in Table II and Table III; and with variables including the monitoring of the treatment in Table IV and Table V. 
Table II. Descriptive statistics of the qualitative variables present before abiraterone acetate treatment (base line). Statistical differences between the patients with higher (group A) and lower (group B) survival rates.

\begin{tabular}{|c|c|c|c|c|c|c|c|}
\hline \multirow{2}{*}{$\frac{\text { Variable }}{\text { Risk group }}$} & \multirow{2}{*}{$\frac{\text { Category }}{1}$} & \multirow{2}{*}{$\frac{\text { All (n) }}{3}$} & \multicolumn{2}{|c|}{ Group A $(\mathrm{n}, \%)$} & \multicolumn{2}{|c|}{ Group B $(\mathrm{n}, \%)$} & \multirow{2}{*}{$\begin{array}{l}p \text {-Value } * \\
p=0.009\end{array}$} \\
\hline & & & 3 & $(100.0 \%)$ & 0 & $(0.0 \%)$ & \\
\hline & 2 & 4 & 3 & $(75.0 \%)$ & 1 & $(25.0 \%)$ & \\
\hline & 3 & 10 & 7 & $(70.0 \%)$ & 3 & $(30.0 \%)$ & \\
\hline & 4 & 10 & 4 & $(40.0 \%)$ & 6 & $(60.0 \%)$ & \\
\hline & 5 & 26 & 10 & $(38.5 \%)$ & 16 & $(61.5 \%)$ & \\
\hline \multirow[t]{5}{*}{ Gleason-ISUP } & 1 & 5 & 4 & $(80.0 \%)$ & 1 & $(20.0 \%)$ & $p>0.05$ \\
\hline & 2 & 6 & 3 & $(50.0 \%)$ & 3 & $(50.0 \%)$ & \\
\hline & 3 & 10 & 6 & $(60.0 \%)$ & 4 & $(40.0 \%)$ & \\
\hline & 4 & 20 & 11 & $(55.0 \%)$ & 9 & $(45.0 \%)$ & \\
\hline & 5 & 11 & 3 & $(27.3 \%)$ & 8 & $(72.7 \%)$ & \\
\hline \multirow[t]{4}{*}{ Previous treatment } & 1 & 6 & 4 & $(66.7 \%)$ & 2 & $(33.3 \%)$ & $p>0.05$ \\
\hline & 2 & 3 & 2 & $(66.7 \%)$ & 1 & $(33.3 \%)$ & \\
\hline & 3 & 9 & 5 & $(55.6 \%)$ & 4 & $(44.4 \%)$ & \\
\hline & 4 & 34 & 15 & $(44.1 \%)$ & 19 & $(55.9 \%)$ & \\
\hline \multirow[t]{3}{*}{ ECOG } & 0 & 12 & 7 & $(58.3 \%)$ & 5 & $(41.7 \%)$ & $p>0.05$ \\
\hline & 1 & 37 & 16 & $(43.2 \%)$ & 21 & $(56.8 \%)$ & \\
\hline & 2 & 4 & 4 & $(100.0 \%)$ & 0 & $(0.0 \%)$ & \\
\hline \multirow[t]{9}{*}{ BPI } & 0 & 8 & 5 & $(62.5 \%)$ & 3 & $(37.5 \%)$ & $p=0.0013$ \\
\hline & 1 & 11 & 8 & $(72.7 \%)$ & 3 & $(27.3 \%)$ & \\
\hline & 2 & 11 & 8 & $(72.7 \%)$ & 3 & $(27.3 \%)$ & \\
\hline & 3 & 8 & 4 & $(50.0 \%)$ & 4 & $(50.0 \%)$ & \\
\hline & 4 & 5 & 1 & $(20.0 \%)$ & 4 & $(80.0 \%)$ & \\
\hline & 5 & 3 & 0 & $(0.0 \%)$ & 3 & $(100.0 \%)$ & \\
\hline & 6 & 4 & 1 & $(25.0 \%)$ & 3 & $(75.0 \%)$ & \\
\hline & 7 & 2 & 0 & $(0.0 \%)$ & 2 & $(100.0 \%)$ & \\
\hline & 8 & 1 & 0 & $(0.0 \%)$ & 1 & $(100.0 \%)$ & \\
\hline
\end{tabular}

*Chi-square. Bold value indicates statistical significance.

Table III. Descriptive statistics of the quantitative variables prior to treatment with abiraterone acetate (base line). Statistical differences between the patients with higher (group A) and lower (group B) survival rates.

\begin{tabular}{|c|c|c|c|c|}
\hline Variable & $\begin{array}{c}\text { All }(\mathrm{n}=53) \\
\text { Median (range) }\end{array}$ & $\begin{array}{l}\text { Group A }(\mathrm{n}=27) \\
\text { Median (range) }\end{array}$ & $\begin{array}{l}\text { Group B }(\mathrm{n}=26) \\
\text { Median (range) }\end{array}$ & $p$-Value* \\
\hline Age (years) & $75(47-88)$ & $72(47-86)$ & $77.5(52-88)$ & $p>0.05$ \\
\hline Time suffering from PC (months) & $33.5(2-128)$ & $38(7-120)$ & $25(2-128)$ & $p=0.0039$ \\
\hline ADT time (months) & $25(2-174)$ & $29(7-174)$ & $22.5(2-99)$ & $p>0.05$ \\
\hline No. of bone lesions & $3(0-20)$ & $2(0-15)$ & $4.5(0-20)$ & $p>0.05$ \\
\hline PSAb (ng/ml) & $20.30(1.27-366)$ & $14.40(1.70-366)$ & $26.56(1.27-365)$ & $p>0.05$ \\
\hline $\mathrm{APb}(\mathrm{UI} / \mathrm{l})$ & $90(41-922)$ & $87(46-281)$ & $93(41-922)$ & $p>0.05$ \\
\hline LDHb (UI/l) & $178(40-527)$ & $165.5(40-233)$ & $214(127-527)$ & $p=0.0031$ \\
\hline
\end{tabular}

*Mann-Whitney $U$-test. Bold value indicates statistical significance.

ROC curves. Time with $\mathrm{PC}, \mathrm{AA}+\mathrm{P}$ treatment duration, $\mathrm{LDHb}$ at $2 \mathrm{w}, \mathrm{AP}$ at $5 \mathrm{~m}$ and $6 \mathrm{~m}$, and PSA at $5 \mathrm{~m}$ and $6 \mathrm{~m}$ were the quantitative variables that showed significant differences between the patient groups and analysed with ROC curves.

Figure 2 shows the obtained ROC curves that differentiate between the patients with longer and shorter survival depending on the variables of time with $\mathrm{PC}$ and $\mathrm{AA}+\mathrm{P}$ treatment duration. Figures 3, 4 and 5 show the obtained ROC curves that differentiate between the patients with longer and shorter survival rates depending on serum $\mathrm{LDHb}$ concentrations, and similarly at $2 \mathrm{w}$, serum AP concentrations at $5 \mathrm{~m}$ and $6 \mathrm{~m}$, and serum PSA concentrations at $5 \mathrm{~m}$ and $6 \mathrm{~m}$.

Table VI shows the AUC and the optimal cut-point values with the corresponding sensitivity and specificity, obtained using the ROC curves analysis method. With regards to the precision of the biochemical markers used to distinguish 
Table IV. Descriptive statistics of the quantitative variables during treatment with AA (monitoring). Statistical differences between the patients with higher (group A) and lower (group B) survival rates.

\begin{tabular}{|c|c|c|c|c|c|c|c|}
\hline \multirow{2}{*}{$\frac{\text { Variable }}{\text { No. lines of treatment }}$} & \multirow{2}{*}{$\frac{\text { Category }}{1}$} & \multirow{2}{*}{$\frac{\text { All (n) }}{37}$} & \multicolumn{2}{|c|}{ Group A (n, \%) } & \multicolumn{2}{|c|}{ Group B (n, \%) } & \multirow{2}{*}{$\frac{p \text {-Value* }}{p>0.05}$} \\
\hline & & & 19 & $(51.4 \%)$ & 18 & $(48.6 \%)$ & \\
\hline & 2 & 9 & 2 & $(22.2 \%)$ & 7 & $(77.8 \%)$ & \\
\hline & 3 & 3 & 3 & $(100 \%)$ & 0 & $(0.0 \%)$ & \\
\hline & 4 & 2 & 1 & $(50.0 \%)$ & 1 & $(50.0 \%)$ & \\
\hline & 5 & 1 & 1 & $(100 \%)$ & 0 & $(0.0 \%)$ & \\
\hline & 6 & 1 & 1 & $(100 \%)$ & 0 & $(0.0 \%)$ & \\
\hline \multirow[t]{3}{*}{ Radiological progression } & 0 & 13 & 8 & $(61.5 \%)$ & 5 & $(38.5 \%)$ & $p>0.05$ \\
\hline & 1 & 36 & 18 & $(50.0 \%)$ & 18 & $(50.0 \%)$ & \\
\hline & 2 & 4 & 1 & $(25.0 \%)$ & 3 & $(75.0 \%)$ & \\
\hline \multirow[t]{2}{*}{ Biochemical progression } & No & 15 & 8 & $(53.3 \%)$ & 7 & $(46.7 \%)$ & $p>0.05$ \\
\hline & Yes & 38 & 19 & $(50.0 \%)$ & 19 & $(50.0 \%)$ & \\
\hline \multirow[t]{2}{*}{ PSA Response } & No & 11 & 5 & $(45.5 \%)$ & 6 & $(54.5 \%)$ & $p>0.05$ \\
\hline & Yes & 42 & 22 & $(52.4 \%)$ & 20 & $(47.6 \%)$ & \\
\hline \multirow[t]{2}{*}{ PSA $30 \%$} & No & 28 & 14 & $(50.0 \%)$ & 14 & $(50.0 \%)$ & $p>0.05$ \\
\hline & Yes & 25 & 13 & $(52.0 \%)$ & 12 & $(48.0 \%)$ & \\
\hline \multirow[t]{2}{*}{ PSA $50 \%$} & No & 20 & 7 & $(35.0 \%)$ & 13 & $(65.0 \%)$ & $p>0.05$ \\
\hline & Yes & 33 & 20 & $(60.6 \%)$ & 13 & $(39.4 \%)$ & \\
\hline \multirow[t]{2}{*}{ PSA $90 \%$} & No & 35 & 13 & $(37.1 \%)$ & 22 & $(62.9 \%)$ & $p=0.0120$ \\
\hline & Yes & 18 & 14 & $(77.8 \%)$ & 4 & $(22.2 \%)$ & \\
\hline PSA Flare & No & 37 & 18 & $(48.6 \%)$ & 19 & $(51.4 \%)$ & $p>0.05$ \\
\hline
\end{tabular}

Bold value indicates statistical significance.

between the patients with longer or shorter survival, it was observed that LDH serum showed more precision when using baseline levels. However, AP and PSA levels were more precise when determined at six months of $\mathrm{AA}+\mathrm{P}$ treatment.

Kaplan-Meier survival curves. The Kaplan-Meier survival curves were used as analysis tools. The variables that showed significant differences between patients with longer and shorter survival were selected as prognostic factors.

In order to carry out the survival rate analysis according to the quantitative variables, the patients were divided into two groups, taking into consideration the optimal cut-point values obtained in the ROC curves. With regards to the biochemical markers, survival rates were analysed using those whose levels showed more precision in the ROC curves (LDHb, AP at $6 \mathrm{~m}$ and PSA at $6 \mathrm{~m}$ ).

Figure 6 shows the Kaplan-Meier curves according to baseline variables (time with PC, risk group, BPI and LDHb). Figure 7 shows them in association with the treatment monitoring variables (treatment time, PSA 90\%, $\mathrm{AP}$ at $6 \mathrm{~m}$ and PSA at $6 \mathrm{~m}$ ). Survival at 30 and 60 months depending on the value of the variables (Table VII) was calculated using the Kaplan-Meier curves.

\section{Discussion}

In this study, a good response to treatment with $\mathrm{AA}+\mathrm{P}$ was observed within the studied series of patients suffering from
mCRPC. Likewise, a large amount of patient clinical data were studied, differentiating patient characteristics and those pertaining to the disease itself linked to higher survival rates.

The pivotal trial COU-AA-302 confirmed the efficiency of using $\mathrm{AA}+\mathrm{P}$ treatment for patients with mCRPC who had not been previously treated with chemotherapy. It significantly improved the overall survival rate, and radiological progression-free survival (rPFS), maintaining an acceptable profile of secondary effects. The mean survival observed in the cohort studied here was below that of the pivotal trial (3-5) (24 months and 34.7 months, respectively). In part, this could be due to the different baseline characteristics of the patients included in both studies. The fact that patients who already presented with metastases were included in the present study - which implies higher tumour incidence and therefore a worse prognosis - could explain the poorer results in terms of survival. Similarly, the fact that the patients included in the present study had already symptoms and suffered from a worse functional status (ECOG 2) - who had specifically been excluded from COUAA-302 - could justify the aforementioned lower survival results. Likewise, these patients were treated with fewer subsequent lines of $\mathrm{AA}+\mathrm{P}$ treatment after progression. The poorer baseline status and the higher tumour incidence presented by some of the patients studied, made the subsequent use of more treatment lines less probable $(67 \%$ of patients within the COU-AA 302, and 30\% in the present case). However, these two studies must be compared with 
Table V. Descriptive statistics of the quantitative variables prior to treatment with abiraterone acetate (base line). Statistical differences between the patients with higher (group A) and lower (group B) survival rates.

\begin{tabular}{|c|c|c|c|c|}
\hline & $\begin{array}{c}\text { All (n=53) } \\
\text { Median (range) }\end{array}$ & $\begin{array}{l}\text { Group A }(\mathrm{n}=27) \\
\text { Median (range) }\end{array}$ & $\begin{array}{l}\text { Group B ( } \mathrm{n}=26) \\
\text { Median (range) }\end{array}$ & $p$-Value* \\
\hline Treatment duration (months) & $16(3-78)$ & $32(6-78)$ & $8.5(3-16)$ & $p<0.0001$ \\
\hline PSA 2 w $(\mathrm{ng} / \mathrm{ml})$ & $24.37(0.87-257)$ & $25.22(3.47-257)$ & $19.93(0.87-250)$ & $p>0.05$ \\
\hline PSA $1 \mathrm{~m}(\mathrm{ng} / \mathrm{ml})$ & $17.96(0.56-240)$ & $10.40(0.81-128)$ & $22.01(0.56-240)$ & $p>0.05$ \\
\hline PSA $2 \mathrm{~m}(\mathrm{ng} / \mathrm{ml})$ & $21.20(0.19-329)$ & $20.21(0.19-329)$ & $22.71(0.48-246)$ & $p>0.05$ \\
\hline PSA 3 m (ng/ml) & $11.88(0.05-244)$ & $8.24(0.05-102)$ & $13.48(0.33-244)$ & $p>0.05$ \\
\hline PSA 4 m (ng/ml) & $12.41(0.16-274)$ & $14.00(0.52-274)$ & $9.83(0.16-208)$ & $p>0.05$ \\
\hline PSA 5 m (ng/ml) & $21.61(0.06-261)$ & $15.73(0.06-261)$ & $43.63(5.50-199)$ & $p=0.0304$ \\
\hline PSA 6 m (ng/ml) & $16.88(0.00-423)$ & $11.06(0.00-423)$ & $47.40(1.47-282)$ & $p=0.0163$ \\
\hline AP 2 w (UI/1) & $89(46-735)$ & $84.5(46-317)$ & $96(54-735)$ & $p>0.05$ \\
\hline AP 1 m (UI/l) & $92(49-361)$ & $83(49-361)$ & $102.5(55-340)$ & $p>0.05$ \\
\hline AP $2 \mathrm{~m}(\mathrm{UI} / 1)$ & $97.5(41-441)$ & $83(46-441)$ & $98(41-299)$ & $p>0.05$ \\
\hline AP 3 m (UI/l) & $84.5(41-559)$ & $58(41-559)$ & $95(54-363)$ & $p>0.05$ \\
\hline AP 4 m (UI/l) & $92.5(38-300)$ & $57(38-130)$ & $95(41-300)$ & $p>0.05$ \\
\hline AP 5 m (UI/l) & $72(44-196)$ & $56(44-139)$ & $86(54-196)$ & $p=0.0180$ \\
\hline AP 6 m (UI/1) & $71(35-306)$ & $56(35-150)$ & $107(42-306)$ & $p=0.0055$ \\
\hline LDH 2 w (UI/l) & $191(133-613)$ & $167(133-613)$ & $210(152-317)$ & $p=0.0424$ \\
\hline LDH 1 m (UI/l) & $189(122-347)$ & $187(141-287)$ & $197(122-347)$ & $p>0.05$ \\
\hline LDH 2 m (UI/l) & $197(137-393)$ & $185(146-253)$ & $209(137-393)$ & $p>0.05$ \\
\hline LDH 3 m (UI/l) & $224(152-360)$ & $225(166-281)$ & $206(152-360)$ & $p>0.05$ \\
\hline LDH 4 m (UI/l) & $200(130-328)$ & $208(165-267)$ & $199(130-328)$ & $p>0.05$ \\
\hline LDH 5 m (UI/l) & $218(177-320)$ & $208(189-308)$ & $219(177-320)$ & $p>0.05$ \\
\hline LDH 6 m (UI/l) & $194(119-525)$ & $196(154-525)$ & $192(119-408)$ & $p>0.05$ \\
\hline
\end{tabular}

*Mann-Whitney $U$-test. Bold values indicate statistical significance.

caution, given the differences in terms of study design and sample size.

However, other recent studies of Asian patients with mCRPC who were treated with AA+P revealed a mean survival of 23.7 (10) and 18.1 months (11), which are similar to the results obtained in the present study. It is important to highlight the interest of the survival results presented by Boegemann et al. (2), which showed a mean survival of 23.3 months. This retrospective observational study included a selection of 481 patients suffering from mCRPC from four European countries. All these patients had not been previously treated with chemotherapy, had received $\mathrm{AA}+\mathrm{P}$ treatment, and had similar baseline characteristics to those presented in the present study: an average of 75 years of age, and functional baseline status (ECOG $0-1$ in $87 \%$, versus $92.4 \%$ in the present series). However, the patients in the present study presented with PSA, AP and LDH baseline values which were lower at the start of treatment: (PSA: $20.30 \mathrm{ng} / \mathrm{ml}$ vs. $56.2 \mathrm{ng} / \mathrm{ml}$, AP: 90 $\mathrm{UI} / 1$ vs. $119 \mathrm{UI} / 1$ and LDH: $178 \mathrm{UI} / 1$ vs. $277 \mathrm{UI} / 1$, respectively). Equally, in the present study the proportion of patients found with initial metastases was higher $(49 \% \mathrm{vs}$. $28.9 \%$ ). The initial objective of Boegemann's group was to determine the time to treatment faillure, meaning the interruption of drug administration due to the progression of the disease, intolerance to the treatment, or death. A mean time of 10 months was observed, versus the 16 months obtained in this study. However, the survival mean was similar in both studies.

As was to be expected, known factors that predict overall survival in mCRPC were also observed in this study, such as the duration of time between disease spread and the PC diagnosis (12), pain intensity measured by the BPI scale (13) and LDH serum levels $(14,15)$. Additionally, the duration of time between the initial PC diagnosis and the start of AA+P treatment, together with the characteristics the disease at diagnosis, were other variables linked to survival in the present series of patients. On the contrary, age, score within the ECOG scale at the start of AA+P treatment, longer ADT response or treatment received once the patient was diagnosed with PC, the ISUP grade, number of bone lesions, or AP and PSA base line serum levels did not significantly impact statistics within the present series of patients, while they are known prognostic factors in other studies.

In keeping with other published studies, the results obtained here point to the possibility that certain clinical parameters can predict patient response to $\mathrm{AA}+\mathrm{P}$ treatment. With this objective in mind, a variable was incorporated that divided the present patients into risk groups, depending on 

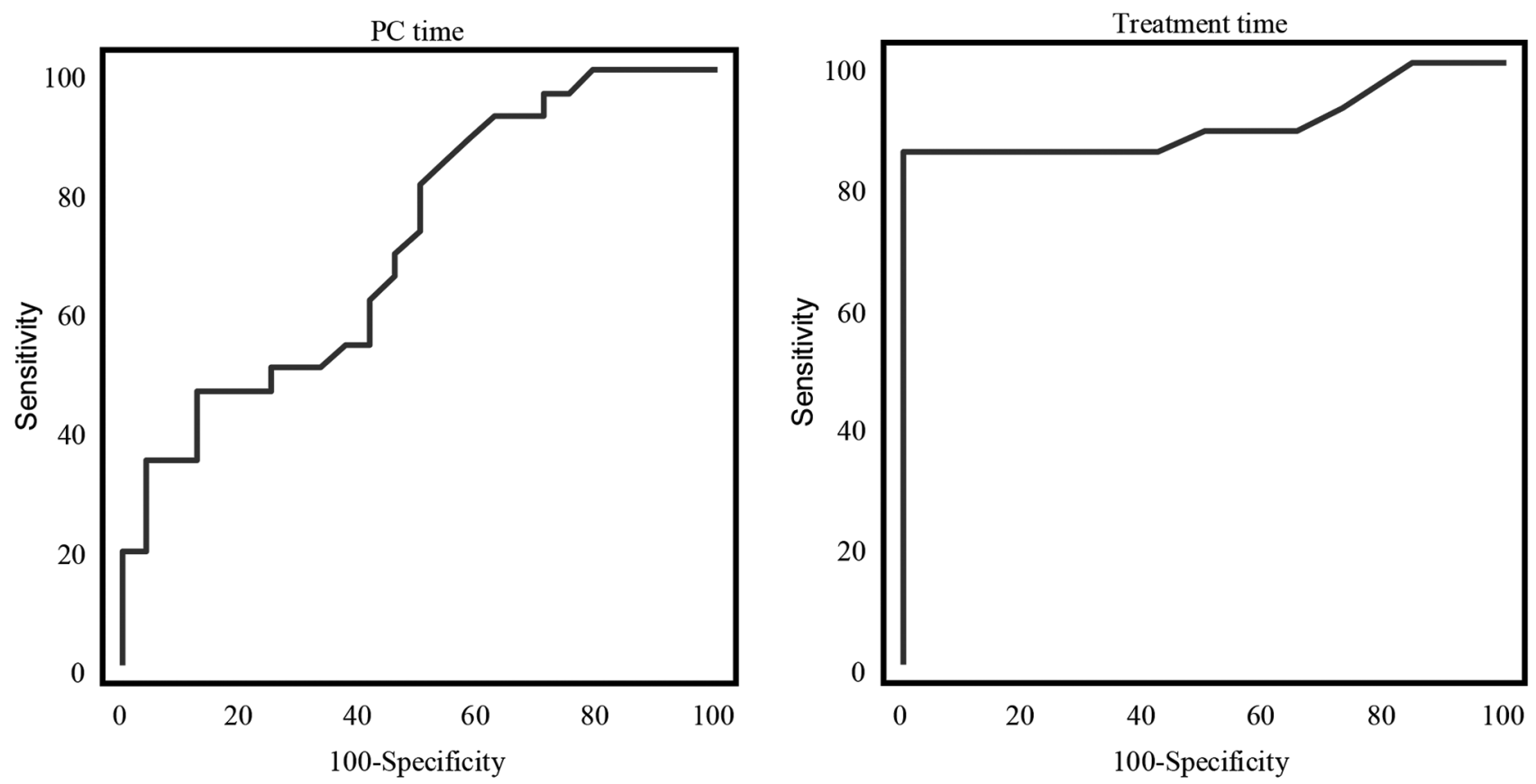

Figure 2. Receiver-operating characteristic curves that differentiate between the patients with higher and lower survival rates depending on the time with prostate cancer and $A A+P$ treatment duration variables.

\section{$\mathrm{LDHb}$}

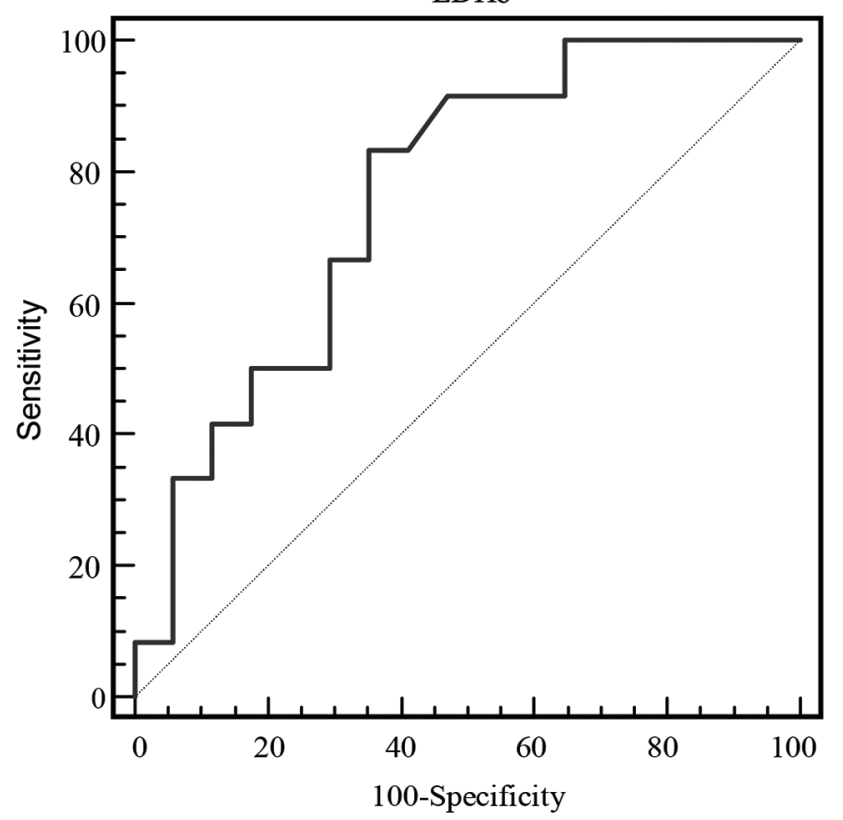

LDH $2 \mathrm{w}$

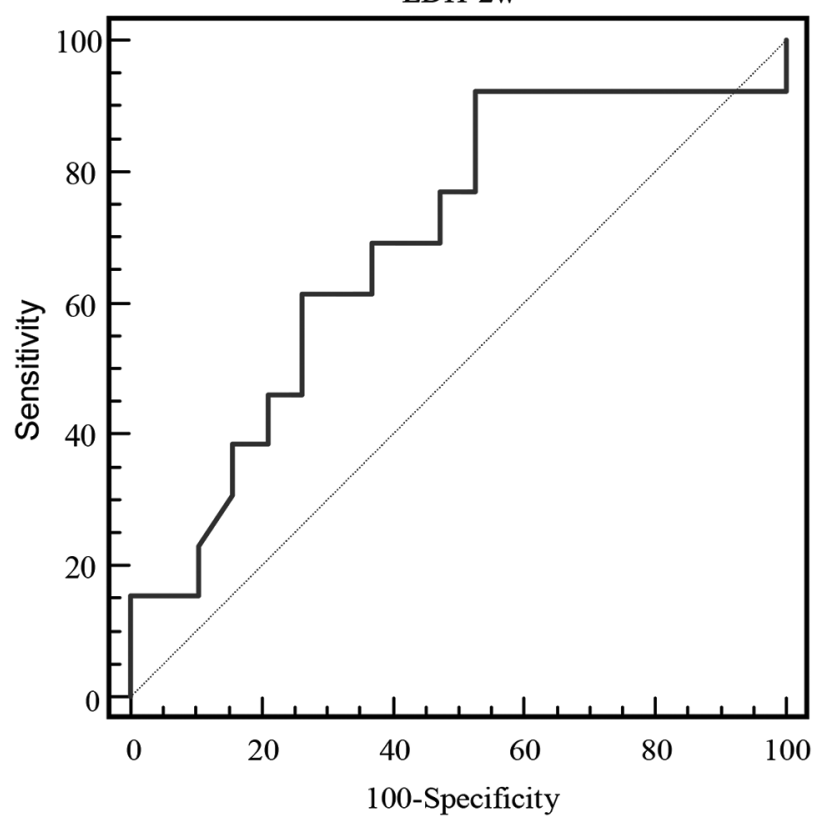

Figure 3. Receiver-operating characteristic curves that differentiate between the patients with higher and lower survival rates depending on LDH baseline serum concentrations, and similarly 2 weeks after $A A+P$ treatment.

the stage presented at the time of PC diagnosis. Thus, patients with localised (low, intermediate and high risk), locally advanced and metastatic PC were included. Some of these patients underwent treatments with curative intent (surgery, RT); others, were treated with the combinartion of RT and ADT; whilst others were treated only with ADT, 

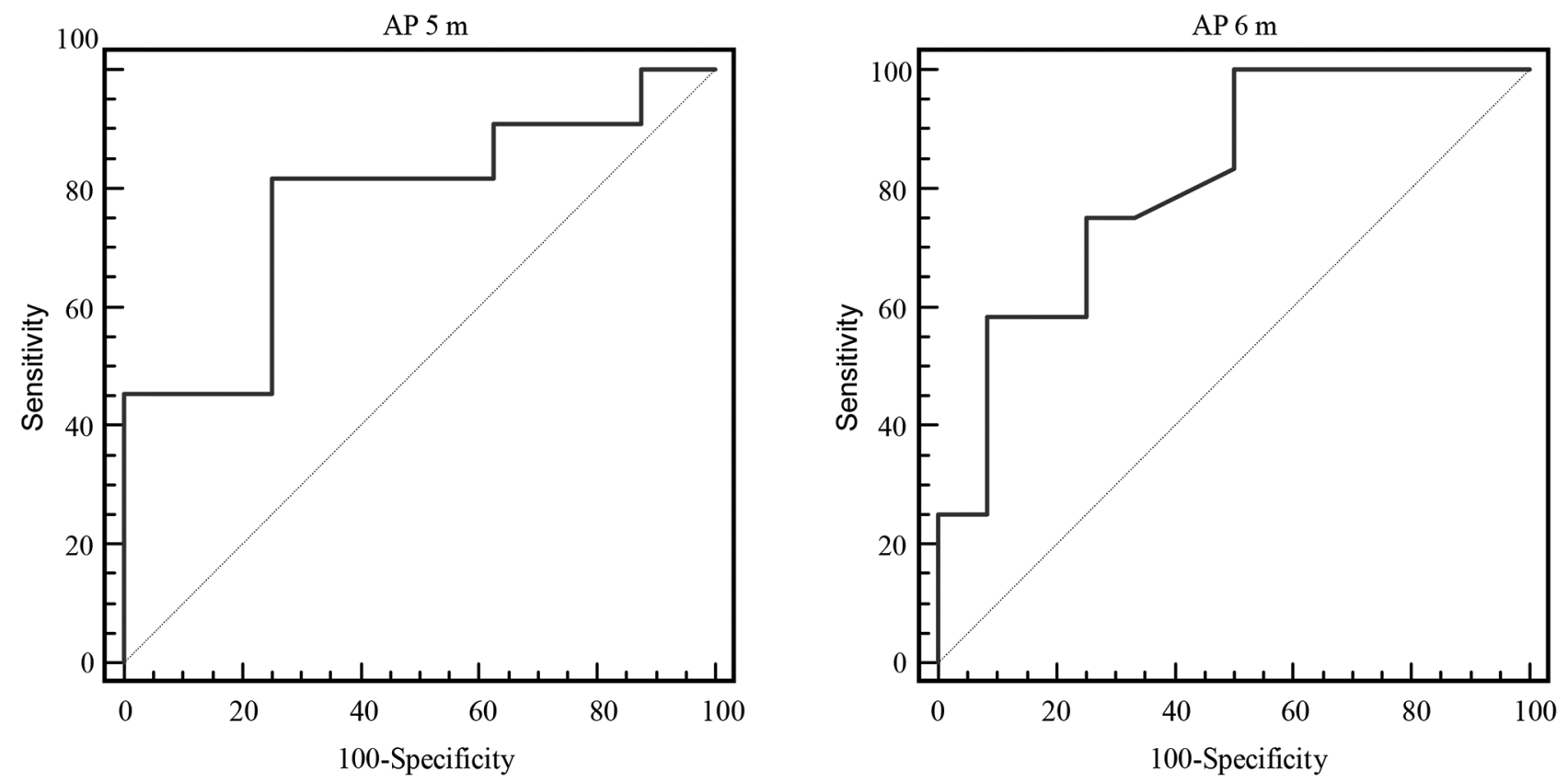

Figure 4. Receiver-operating characteristic curves that differentiate between the patients with higher and lower survival rates depending on alkaline phosphatase serum concentrations at 5 and 6 months of $A A+P$ treatment.
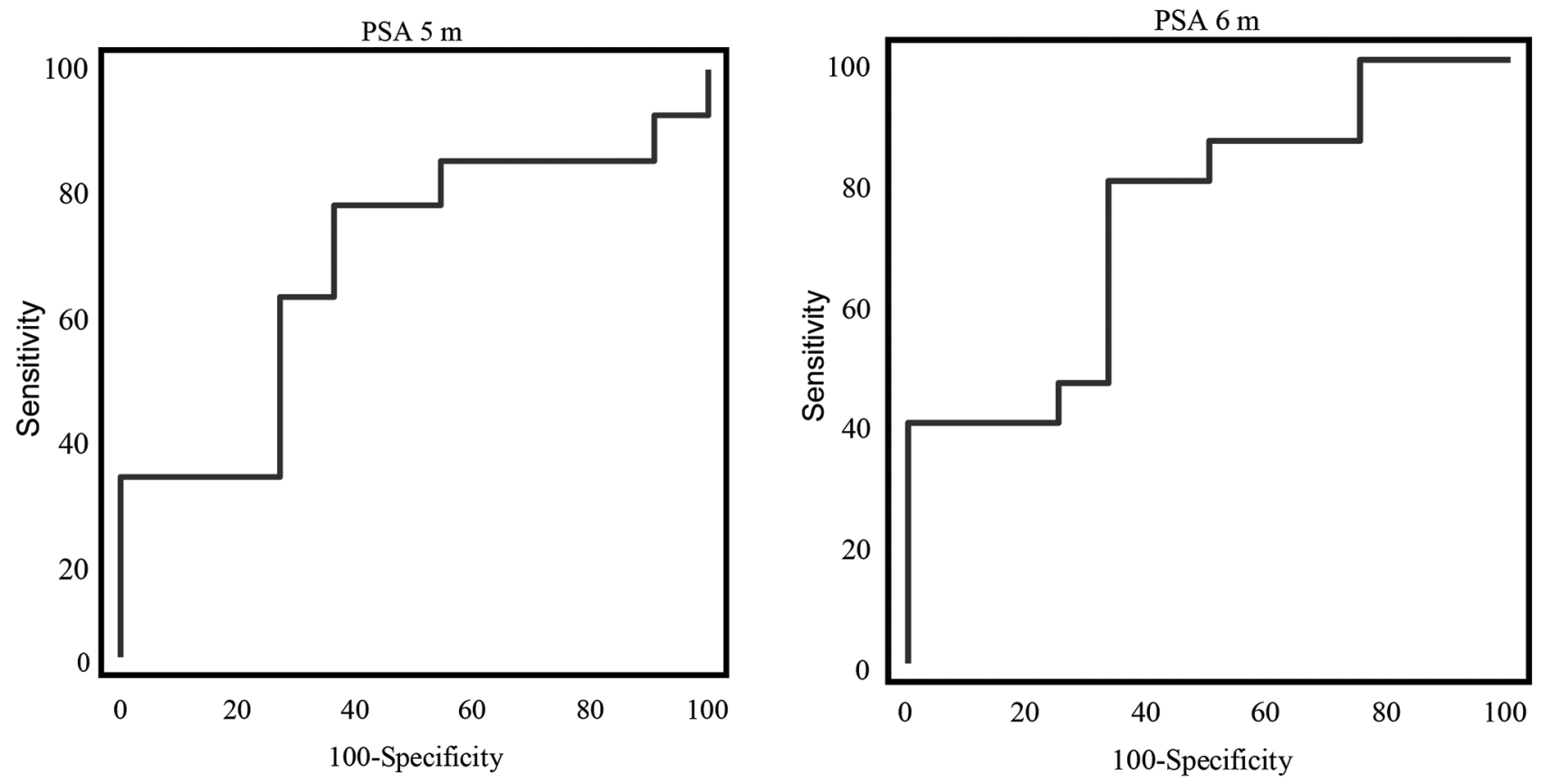

Figure 5. Receiver-operating characteristic curves that differentiate between the patients with higher and lower survival rates depending on PSA serum concentrations at 5 and 6 months of $A A+P$ treatment.

prompted by a clinical decision, because at the time of diagnosis, bone metastasis was already present, or because at the time it was the only available treatment for the disease.
It is, therefore, logical to infer, that the evolution of the disease until the castration-resistant phase is reached would differ in each of these patient sub-groups. This can be 
Table VI. Areas under the curve (AUC) of diagnostic precision, optimal cut-point values, sensitivity and specificity of quantitative values, which showed significant differences between patients with higher and lower survival rates.

\begin{tabular}{|c|c|c|c|c|}
\hline Variable & $\begin{array}{c}\text { AUC } \\
(95 \% \mathrm{CI})\end{array}$ & Cut-off & $\begin{array}{l}\text { Sensibility } \\
(95 \% \mathrm{CI})\end{array}$ & $\begin{array}{c}\text { Specificity } \\
(95 \% \mathrm{CI})\end{array}$ \\
\hline Time suffering from PC & $\begin{array}{c}0.711 \\
(0.515-0.786)\end{array}$ & $>45$ months & $\begin{array}{c}46.2 \% \\
(26.6-66.6)\end{array}$ & $\begin{array}{c}87.5 \% \\
(67.6-97.2)\end{array}$ \\
\hline Treatment time & $\begin{array}{c}0.899 \\
(0.785-0.964)\end{array}$ & $>16$ months & $\begin{array}{c}85.2 \% \\
(66.3-95.7)\end{array}$ & $\begin{array}{c}100 \% \\
(86.7-100)\end{array}$ \\
\hline $\mathrm{LDHb}$ & $\begin{array}{c}0.762 \\
(0.569-0.899)\end{array}$ & $\leq 163 \mathrm{UI} / 1$ & $\begin{array}{c}50.0 \% \\
(21.2-78.8)\end{array}$ & $\begin{array}{c}82.4 \% \\
(56.6-96.0)\end{array}$ \\
\hline LDH 2 w & $\begin{array}{c}0.690 \\
(0.503-0.841)\end{array}$ & $\leq 159 \mathrm{UI} / 1$ & $\begin{array}{c}38.5 \% \\
(14.0-68.4)\end{array}$ & $\begin{array}{c}84.2 \% \\
(60.4-96.4)\end{array}$ \\
\hline AP $5 \mathrm{~m}$ & $\begin{array}{c}0.773 \\
(0.526-0.929)\end{array}$ & $\leq 53 \mathrm{UI} / 1$ & $\begin{array}{c}45.5 \% \\
(16.9-76.5)\end{array}$ & $\begin{array}{c}100 \% \\
(62.9-100)\end{array}$ \\
\hline AP $6 \mathrm{~m}$ & $\begin{array}{c}0.812 \\
(0.602-0.940)\end{array}$ & $\leq 56 \mathrm{UI} / 1$ & $\begin{array}{c}58.3 \% \\
(27.8-84.7)\end{array}$ & $\begin{array}{c}91.7 \% \\
(61.5-98.6)\end{array}$ \\
\hline PSA $5 \mathrm{~m}$ & $\begin{array}{c}0.671 \\
(0.521-0.800)\end{array}$ & $\leq 2.74 \mathrm{ng} / \mathrm{ml}$ & $\begin{array}{c}30.8 \% \\
(14.4-51.8)\end{array}$ & $\begin{array}{c}100 \% \\
(84.4-100)\end{array}$ \\
\hline PSA $6 \mathrm{~m}$ & $\begin{array}{c}0.739 \\
(0.555-0.809)\end{array}$ & $\leq 0.95 \mathrm{ng} / \mathrm{ml}$ & $\begin{array}{c}40.0 \% \\
(16.4-67.7)\end{array}$ & $\begin{array}{c}100 \% \\
(85.6-100)\end{array}$ \\
\hline
\end{tabular}

CI: Confidence interval.

attributed to tumour incidence, and to the treatment or lines of treatment received until disease progression.

The results obtained here suggest a lower benefit derived from long-term $\mathrm{AA}+\mathrm{P}$ treatment in patients with high initial metastatic incidence, who, until the disease progressed, had only been treated with ADT. Nonetheless, the LATITUDE analysis (16) in patients with high-risk metastatic castration-sensitive PC, supports the addition of AA+P with ADT compared with ADT alone. This was in terms of survival benefits, by significantly increasing their overall survival rate and rPFS.

In this study, the patients with the longer survival, showed a longer time span between initial PC diagnosis and the development of castration resistance, followed by the consequent start of $\mathrm{AA}+\mathrm{P}$ treatment. Hence, a duration of over 45 months was significantly linked to longer survival. Contrary to what was expected, ADT time was not linked to longersurvival of patients in the present work. Numerous studies have confirmed that a shorter response time to ADT is linked to lower PFS and overall survival rates (17). In keeping with this, Fan et al. (10) observed that longer duration to ADT response ( $\geq 18$ months) was a determining factor for the survival of patients treated with AA+P. They suggested that patients administered ADT during a short period of time until castration resistance is developed $(<18$ months), could benefit from initial systemic chemotherapy treatment. Within the previously mentioned Boegemann et al. (2) study, the patients who had longer time between the start of their hormone deprivation treatment and the development of castration resistance, benefited from more time until treatment failure was reached. The present study included metastatic patients who were initially treated with
Table VII. Survival probability at 30 and 60 months depending on the variables analysed with Kaplan-Meier curves.

\begin{tabular}{|c|c|c|c|c|}
\hline \multirow[t]{2}{*}{ Variable } & \multirow[t]{2}{*}{ Value } & \multicolumn{2}{|c|}{ Survival probability } & \multirow[b]{2}{*}{$p$-Value } \\
\hline & & 30 months & 60 months & \\
\hline \multirow{2}{*}{$\begin{array}{l}\text { Time suffering } \\
\text { from PC }\end{array}$} & $>45$ months & $75.0 \%$ & $41.7 \%$ & \multirow{2}{*}{$p=0.0270$} \\
\hline & $\leq 45$ months & $64.3 \%$ & $0 \%$ & \\
\hline \multirow[t]{2}{*}{ Risk group } & Groups 1-4 & $76.5 \%$ & $29.4 \%$ & \multirow[t]{2}{*}{$p=0.015$} \\
\hline & Group 5 & $60.0 \%$ & $0 \%$ & \\
\hline \multirow[t]{2}{*}{ BPI } & $0-2$ & $76.2 \%$ & $23.8 \%$ & \multirow[t]{2}{*}{$p=0.0042$} \\
\hline & $3-8$ & $50.0 \%$ & $0 \%$ & \\
\hline \multirow[t]{2}{*}{$\mathrm{LDHb}$} & $\leq 163 \mathrm{UI} / 1$ & $60.0 \%$ & $40.0 \%$ & \multirow[t]{2}{*}{$p=0.0466$} \\
\hline & >163 UI/1 & $57.1 \%$ & $0 \%$ & \\
\hline \multirow{2}{*}{$\begin{array}{l}\text { Treatment } \\
\text { time }\end{array}$} & $>16$ months & $73.9 \%$ & $21.7 \%$ & \multirow[t]{4}{*}{$p=0.0337$} \\
\hline & $\leq 16$ months & $33.3 \%$ & $0 \%$ & \\
\hline \multirow[t]{2}{*}{ PSA $90 \%$} & Yes & \multirow{2}{*}{\multicolumn{2}{|c|}{$p>0.05$}} & \\
\hline & No & & & \\
\hline \multirow[t]{2}{*}{ AP $6 \mathrm{~m}$} & $\leq 56 \mathrm{UI} / 1$ & $83.3 \%$ & $33.3 \%$ & \multirow[t]{4}{*}{$p=0.0418$} \\
\hline & $>56 \mathrm{UI} / 1$ & $42.9 \%$ & $14.3 \%$ & \\
\hline \multirow[t]{2}{*}{ PSA $6 \mathrm{~m}$} & $\leq 0.95 \mathrm{ng} / \mathrm{ml}$ & & $p>0.05$ & \\
\hline & $>0.95 \mathrm{ng} / \mathrm{ml}$ & & & \\
\hline
\end{tabular}

*Chi-square. Bold values indicate statistical significance.

ADT; the disease at this stage intrinsically implies high tumour burden, with a high probability of tumour behaving aggressively, which in turn impacts the value of the ADT time variable found in the present series of patients.

Hence, patients experiencing lower pain intensity at the start of $\mathrm{AA}+\mathrm{P}$ treatment (BPI 0-2), show higher survival probability. This is in keeping with a post-hoc analysis of the 

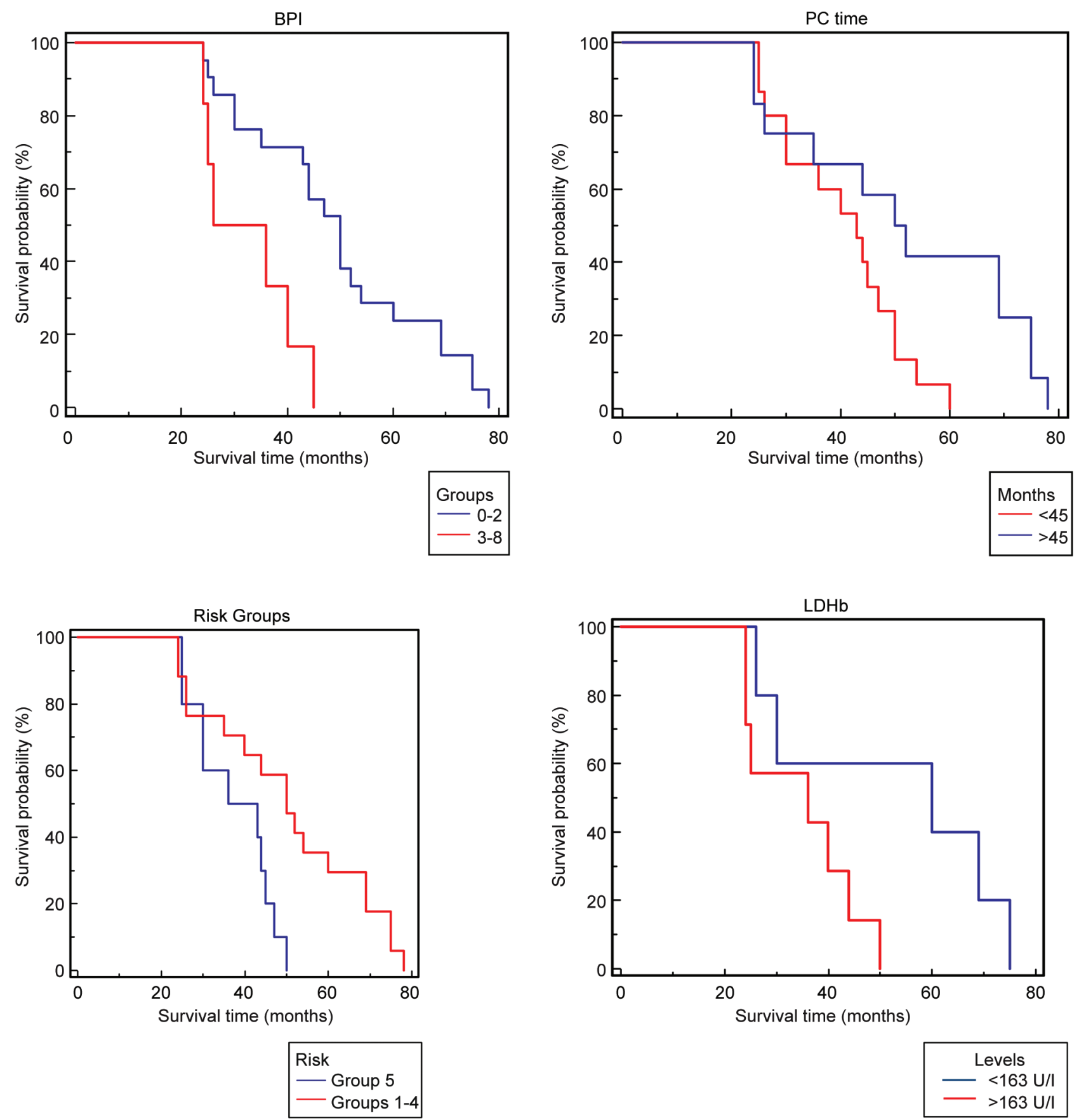

Figure 6. Kaplan-Meier survival curves regarding baseline variables: time with PC, risk group brief pain inventory and LDHb.

COU-AA-302 study (18), which showed that the clinical benefits of $\mathrm{AA}+\mathrm{P}$ treatment are higher for patients who had less pain at the start of treatment (BPI 0-1). Armstrong et al. (19) analysed patients from the Prevail study data base, with the objective of defining prognostic and predictive variables for overall survival rates. They validated a prognostic model which included, among others, 11 pain intensity variables at treatment onset using Enzalutamide. They found that the lower the baseline pain, the higher the survival rates.

The majority of the tumour biomarkers studied carried prognostic value at the time of diagnosis, since their concentration was related to the size of the tumour (20). Their true clinical value, however, resides in patient followup, to detect early relapse and also to evaluate the 

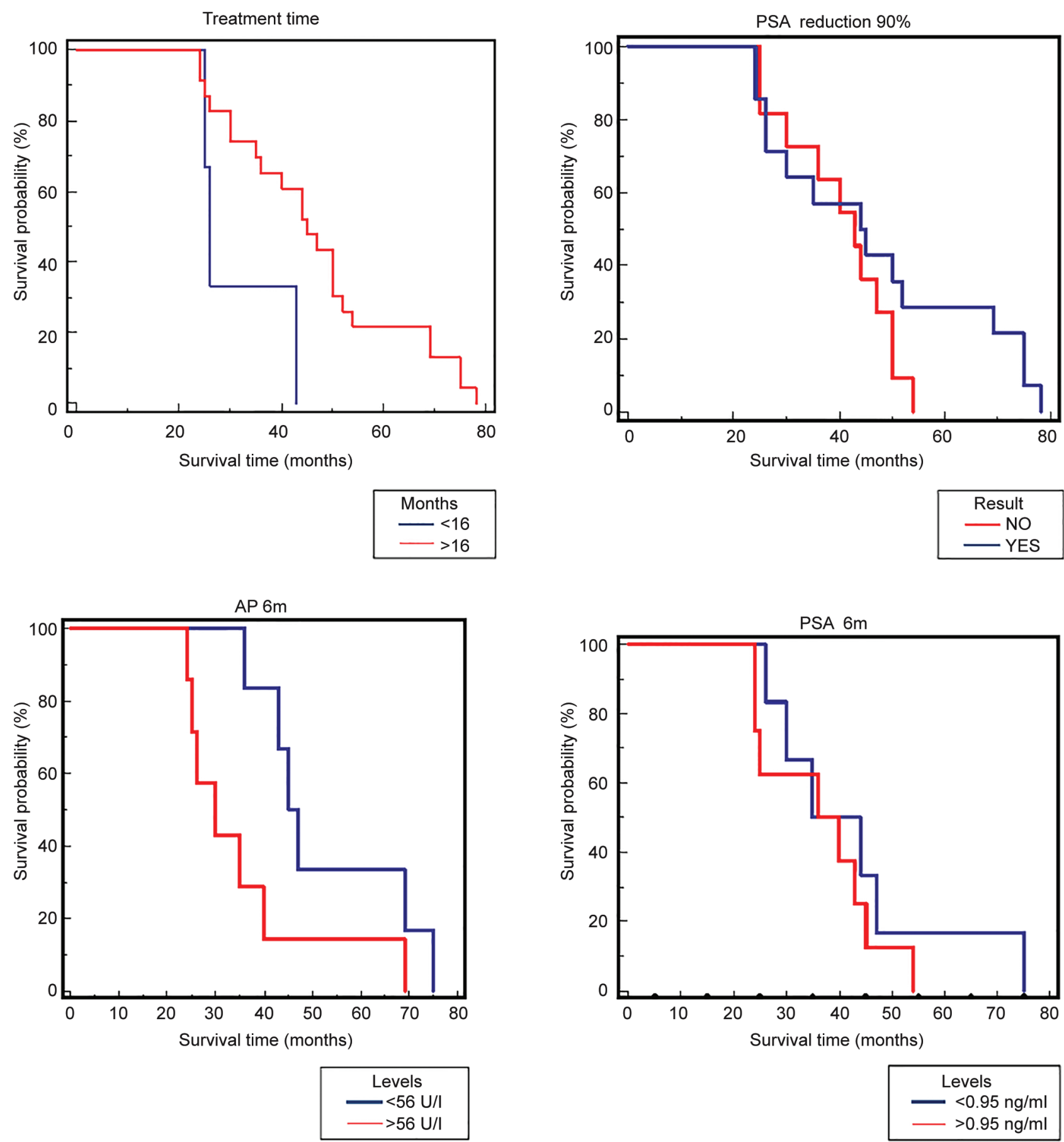

Figure 7. Kaplan-Meier survival curves regarding monitoring variables: treatment time, PSA 90\%, alkaline phosphatase (AP) at 6 months and PSA at 6 months.

effectiveness of the prescribed treatment. Within the broad range of markers found in literature, some have been validated as useful serum markers from the prognostic point of view, and that is why PSA, LDH and AP are included in the present analytical determinations.
$\mathrm{LDH}$ is an important marker of swelling and tissue damage (21). In this study, the LDH serum concentration at the start of $\mathrm{AA}+\mathrm{P}$ treatment was significantly higher in patients with shorter survival. Using the ROC curve, an optimal cut-point value of $163 \mathrm{U} / 1$ was obtained to differentiate between 
patients with longer and shorter survival. The Kaplan-Meier curves, showed as poor prognostic factors LDHb serum levels higher than $163 \mathrm{U} / 1$, linked to a survival below 60 months. Ryan et al. (6), using the data from patients treated with $\mathrm{AA}+\mathrm{P}$ extracted from COU-AA-302, increase this threshold to levels above $234 \mathrm{U} / 1$.

The role that the AP serum biomarker plays, which in bladder and gastric cancers is indicative of an independent bone metastasis risk factor, is not as clear in PC cases. It is thought that at the start of metastatic disease, AP marks the bone change (22). A recent meta-analytic study, based on data from 63 studies, reports that high AP at baseline is associated with poor overall survival rates and PFS in patients suffering from PC (23). Likewise, a series of studies have used baseline levels and AP changes during treatment with $\mathrm{AA}+\mathrm{P}$ as tools to identify patient groups with different risks of bone lesion progression $(2,13,22,23)$. Thus, baseline levels of AP $\leq 119 \mathrm{U} / 1$ were linked to longer treatment time and a longer span until the disease progression to mCRPC (2). Similarly, a recent study that accesses the data of 546 patients from the COU-AA-302 study, points out that an increase in AP values above $20 \%$ during treatment with $(\mathrm{AA}+\mathrm{P})$ is related to bone lesion progression (13). The present study did not find significant differences between patients with longer and shorter survival when using AP base line levels; yet it was a prognostic marker of the AP serum levels at six months, resulting in an optimal cut-point value of $56 \mathrm{U} / 1$. The Kaplan-Meier curve showed a very low survival rate after 60 months $(14.3 \%)$ in patients with levels of AP $6 \mathrm{~m}>56 \mathrm{U} / 1$.

The PSA response after having initiated $\mathrm{AA}+\mathrm{P}$ treatment is a positive prognostic factor if data from studies such as COU-AA-302 and 301 is taken into account, where a correlation between the overall survival rate and PSA kinetics was established (24). In contrast, the lack of PSA response could be considered as a potential biomarker for patient selection - it could be eliminated and substituted by an alternative or an additional marker. Within the present study, 16 patients exhibited a sharp increase in PSA levels at the start of treatment (known as "PSA flare"), yet no significant differences were found in their clinical results. Although the Prostate Cancer Clinical Trials Working Group (PCWG2) (25) group criteria suggest that early changes in PSA (before the 12th week) should not be taken into consideration when determining the response to $\mathrm{AA}+\mathrm{P}$ treatment, different studies have shown a strong link between early PSA level reduction and overall survival rates and rPFS $(26,27)$. Consequently, and given the frequent occurrence of this phenomenon as well as the inconsistent data, it is recommended that PSA levels are interpreted from week 12, and that early interruption of those patients' treatment should be avoided (27). However, this decision should be revisited when no biochemical response beyond week 12 is observed.
Poon et al. (11) demonstrated that there was no survival improvement in patients with no response to PSA after 12 weeks and when treatment was maintained.

A meticulous interpretation of PSA levels from 12 weeks onwards is suggested, to evaluate whether treatment should be suspended in patients for whom no clinical benefit, even in imaging tests (carried out during this 12th week), can be observed.

In this series of patients, PSA levels at six months showed higher precision in differentiating between patients with longer and shorter survival, with an optimal cut-point value of $0.95 \mathrm{ng} / \mathrm{ml}$. Conversely, significant differences in the Kaplan-Meier curve were not found, so survival at 60 months of treatment could not be predicted. This could be due to the small sample size of the present study.

In turn, a $30 \%, 50 \%$ and $90 \%$ decrease in PSA levels, as well as measurements connected to PSA kinetics, are associated with survival and radiological progression in different studies (26). In the present study, a 90\% PSA reduction was linked to a higher survival rate, although once again survival at 60 months of treatment could not be predicted.

In summary, and after having interpreted the results gathered within this series of patients, the following prognostic markers can be defined: 1) Baseline LDH and AP at six months are considered as markers with a highly demonstrated prognostic value: significant differences between patients with longer and shorter survival were exhibited, as well as statistical significance shown in the Kaplan-Meier curve, resulting in an estimation of survival at 60 months. 2) PSA levels at six months is a possible prognostic marker: significant differences between patients with higher and lower survival rates were exhibited, but not reflected in the Kaplan-Meier curve.

These serum markers can be prognostic factors of the evolution and follow-up of patients with mCRPC, considering that there are different methods to determine them, and that differences can be found when quantifying them.

This work identified prognostic factors in patients with mCRPC treated with $\mathrm{AA}+\mathrm{P}$, studying a large number of variables, analysing the differences between patients with longer and shorter survival rates, applying ROC curves analysis and Kaplan-Meier survival curves. One of the observed limitations is the small number of studied patients $(n=53)$, which was insufficient to carry out a multi-variable analysis and to develop a probability model. Studies with a higher number of patients are necessary, as they allow for multi-variable analysis, and can confirm the prognostic factors identified in the present study.

The retrospective design of this study adds certain limitations. The survival in patients who were still alive after having gathered all the data was the survival at said point (which was always above 24 months, as it was the minimum 
follow-up period established so that they could be included in the higher survival group of this study), yet there was no way of knowing the exact survival age that these patients could reach. Nonetheless, the survival rate of the deceased patients during the study was precise.

\section{Conclusion}

The results of this study present new evidence regarding the characteristics and management of mCRPC patients treated with $\mathrm{AA}+\mathrm{P}$ during usual clinical practice. Although some of the baseline characteristics were unfavourable in some patients (metastatic debut), a good response was achieved in the patients treated with $\mathrm{AA}+\mathrm{P}$. The majority of patients suffering from $\mathrm{mCRPC}$ treated with $\mathrm{AA}+\mathrm{P}$ reached a life expectancy beyond two years. The factors with higher prognostic accuracy were time suffering from PC, risk group to which the patient belonged at the time of the initial PC diagnosis, pain intensity measured with the BPI scale, $\mathrm{AA}+\mathrm{P}$ treatment time and tumour markers (LDH serum concentration at $\mathrm{AA}+\mathrm{P}$ treatment start, $\mathrm{AP}$ and PSA serum levels at six months of treatment). More experience in terms of managing the disease, together with better patient selection, and a broader range of treatments which will in future be available for each phase of the illness, will contribute to a significant improvement in the aoutcomes for this group of patients in the future.

\section{Conflicts of Interest}

All Authors declare no conflicts of interest in relation to this study.

\section{Authors' Contributions}

MEJR: Conceptualization, Methodology, Writing-Original draft, Formal analysis, Investigation, Data acquisition. MCG: Methodology, Writing-Original draft, Investigation, Data acquisition. JCNS: Methodology, Writing- Original draft, Investigation, Data acquisition. MASH: Supervision, WritingReview and Editing. JDS: Conceptualization, Methodology, Writing-Original draft, Formal analysis, Data curation, laboratory tests and Statistical analysis. All Authors read and approved the final manuscript.

\section{References}

1 Perlmutter MA and Lepor H: Androgen deprivation therapy in the treatment of advanced prostate cancer. Rev Urol 9 Suppl 1: S3-S8, 2007. PMID: 17387371.

2 Boegemann M, Khaksar S, Bera G, Birtle A, Dopchie C, Dourthe LM, Everaert E, Hatzinger M, Hercher D, Hilgers W, Matus G, Alvarez LG, Antoni L, Lukac M, Pissart G, Robinson $\mathrm{P}$ and Elliott T: Abiraterone acetate plus prednisone for the Management of Metastatic Castration-Resistant Prostate Cancer (mCRPC) without prior use of chemotherapy: report from a large, international, real-world retrospective cohort study. BMC Cancer 19(1): 60, 2019. PMID: 30642291. DOI: 10.1186/ s12885-019-5280-6

3 Ryan CJ, Smith MR, de Bono JS, Molina A, Logothetis CJ, de Souza P, Fizazi K, Mainwaring P, Piulats JM, Ng S, Carles J, Mulders PF, Basch E, Small EJ, Saad F, Schrijvers D, Van Poppel H, Mukherjee SD, Suttmann H, Gerritsen WR, Flaig TW, George DJ, Yu EY, Efstathiou E, Pantuck A, Winquist E, Higano CS, Taplin ME, Park Y, Kheoh T, Griffin T, Scher HI, Rathkopf DE and COU-AA-302 Investigators: Abiraterone in metastatic prostate cancer without previous chemotherapy. N Engl J Med 368(2): 138-148, 2013. PMID: 23228172. DOI: 10.1056/ NEJMoa1209096

4 Beer TM, Armstrong AJ, Rathkopf DE, Loriot Y, Sternberg CN, Higano CS, Iversen P, Bhattacharya S, Carles J, Chowdhury S, Davis ID, de Bono JS, Evans CP, Fizazi K, Joshua AM, Kim CS, Kimura G, Mainwaring P, Mansbach H, Miller K, Noonberg SB, Perabo F, Phung D, Saad F, Scher HI, Taplin ME, Venner PM, Tombal $\mathrm{B}$ and PREVAIL Investigators: Enzalutamide in metastatic prostate cancer before chemotherapy. N Engl J Med 371(5): 424-433, 2014. PMID: 24881730. DOI: 10.1056/ NEJMoa1405095

5 Ryan CJ, Smith MR, Fizazi K, Saad F, Mulders PF, Sternberg CN, Miller K, Logothetis CJ, Shore ND, Small EJ, Carles J, Flaig TW, Taplin ME, Higano CS, de Souza P, de Bono JS, Griffin TW, De Porre P, Yu MK, Park YC, Li J, Kheoh T, Naini V, Molina A, Rathkopf DE and COU-AA-302 Investigators: Abiraterone acetate plus prednisone versus placebo plus prednisone in chemotherapy-naive men with metastatic castration-resistant prostate cancer (COU-AA-302): final overall survival analysis of a randomised, double-blind, placebocontrolled phase 3 study. Lancet Oncol 16(2): 152-160, 2015. PMID: 25601341. DOI: 10.1016/S1470-2045(14)71205-7

6 Ryan CJ, Kheoh T, Li J, Molina A, De Porre P, Carles J, Efstathiou E, Kantoff PW, Mulders PFA, Saad F and Chi KN: Prognostic index model for progression-free survival in chemotherapy-naïve metastatic castration-resistant prostate cancer treated with abiraterone acetate plus prednisone. Clin Genitourin Cancer, 2017. PMID: 28844792. DOI: 10.1016/ j.clgc.2017.07.014

7 Fizazi K, Flaig TW, Stöckle M, Scher HI, de Bono JS, Rathkopf DE, Ryan CJ, Kheoh T, Li J, Todd MB, Griffin TW, Molina A and Ohlmann $\mathrm{CH}$ : Does Gleason score at initial diagnosis predict efficacy of abiraterone acetate therapy in patients with metastatic castration-resistant prostate cancer? An analysis of abiraterone acetate phase III trials. Ann Oncol 27(4): 699-705, 2016. PMID: 26609008. DOI: 10.1093/annonc/mdv545

8 Martin LJ, Alibhai SMH, Komisarenko M, Timilshina N and Finelli A: Identification of subgroups of metastatic castrateresistant prostate cancer (mCRPC) patients treated with abiraterone plus prednisone at low- $v s$. high-risk of radiographic progression: An analysis of COU-AA-302. Can Urol Assoc J 13(6): 192-200, 2019. PMID: 30407155. DOI: 10.5489/ cuaj. 5586

9 Pinart M, Kunath F, Lieb V, Tsaur I, Wullich B, Schmidt S and German Prostate Cancer Consortium (DPKK): Prognostic models for predicting overall survival in metastatic castrationresistant prostate cancer: a systematic review. World J Urol 38(3): 613-635, 2020. PMID: 30554274. DOI: 10.1007/s00345018-2574-2 
10 Fan L, Dong B, Chi C, Wang Y, Gong Y, Sha J, Pan J, Shangguan X, Huang Y, Zhou L and Xue W: Abiraterone acetate for chemotherapy-naive metastatic castration-resistant prostate cancer: a single-centre prospective study of efficacy, safety, and prognostic factors. BMC Urol 18(1): 110, 2018. PMID: 30509237. DOI: 10.1186/s12894-018-0416-6

11 Poon DM, Chan K, Lee SH, Chan TW, Sze H, Lee EK, Lam D and Chan MF: Abiraterone acetate in metastatic castrationresistant prostate cancer - the unanticipated real-world clinical experience. BMC Urol 16: 12, 2016. PMID: 27001043. DOI: 10.1186/s12894-016-0132-Z

12 Martin LJ, Alibhai SMH, Komisarenko M, Timilshina N and Finelli A: Identification of subgroups of metastatic castrateresistant prostate cancer (mCRPC) patients treated with abiraterone plus prednisone at low- $v s$. high-risk of radiographic progression: An analysis of COU-AA-302. Can Urol Assoc J 13(6): 192-200, 2019. PMID: 30407155. DOI: 10.5489/ cuaj.5586

13 Halabi S, Lin CY, Small EJ, Armstrong AJ, Kaplan EB, Petrylak D, Sternberg CN, Shen L, Oudard S, de Bono J and Sartor O: Prognostic model predicting metastatic castration-resistant prostate cancer survival in men treated with second-line chemotherapy. J Natl Cancer Inst 105(22): 1729-1737, 2013. PMID: 24136890. DOI: 10.1093/jnci/djt280

14 Chi KN, Kheoh T, Ryan CJ, Molina A, Bellmunt J, Vogelzang NJ, Rathkopf DE, Fizazi K, Kantoff PW, Li J, Azad AA, Eigl BJ, Heng DY, Joshua AM, de Bono JS and Scher HI: A prognostic index model for predicting overall survival in patients with metastatic castration-resistant prostate cancer treated with abiraterone acetate after docetaxel. Ann Oncol 27(3): 454-460, 2016. PMID: 26685010. DOI: 10.1093/annonc/mdv594

15 Khalaf DJ, Avilés CM, Azad AA, Sunderland K, Todenhöfer T, Eigl BJ, Finch D, Le L, Atwell A, Keith B, Kollmannsberger C and $\mathrm{Chi} \mathrm{KN}$ : A prognostic model for stratifying clinical outcomes in chemotherapy-naive metastatic castration-resistant prostate cancer patients treated with abiraterone acetate. Can Urol Assoc J 12(2): E47-E52, 2018. PMID: 29381456. DOI: 10.5489/cuaj.4600

16 Fizazi K, Tran N, Fein L, Matsubara N, Rodriguez-Antolin A, Alekseev BY, Özgüroğlu M, Ye D, Feyerabend S, Protheroe A, De Porre P, Kheoh T, Park YC, Todd MB, Chi KN and LATITUDE Investigators: Abiraterone plus prednisone in metastatic, castration-sensitive prostate cancer. N Engl J Med 377(4): 352-360, 2017. PMID: 28578607. DOI: 10.1056/ NEJMoa1704174

17 Loriot Y, Eymard JC, Patrikidou A, Ileana E, Massard C, Albiges L, Di Palma M, Escudier B and Fizazi K: Prior long response to androgen deprivation predicts response to next-generation androgen receptor axis targeted drugs in castration resistant prostate cancer. Eur J Cancer 51(14): 1946-1952, 2015. PMID: 26208462. DOI: 10.1016/j.ejca.2015.06.128

18 Miller K, Carles J, Gschwend JE, Van Poppel H, Diels J and Brookman-May SD: The phase 3 COU-AA-302 study of abiraterone acetate plus prednisone in men with chemotherapynaïve metastatic castration-resistant prostate cancer: Stratified analysis based on pain, prostate-specific antigen, and Gleason score. Eur Urol 74(1): 17-23, 2018. PMID: 28939004. DOI: 10.1016/j.eururo.2017.08.035

19 Armstrong AJ, Lin P, Higano CS, Sternberg CN, Sonpavde G, Tombal B, Templeton AJ, Fizazi K, Phung D, Wong EK,
Krivoshik A and Beer TM: Development and validation of a prognostic model for overall survival in chemotherapy-naïve men with metastatic castration-resistant prostate cancer. Ann Oncol 29(11): 2200-2207, 2018. PMID: 30202945. DOI: 10.1093/annonc/mdy406

20 Tumor Markers. National Cancer Institute. Available at: https://www.cancer.gov/about-cancer/diagnosis-staging/ diagnosis/tumor-markers-fact-sheet [Last accessed on May 30, 2021]

21 Santotoribio JD and Jiménez Romero ME: Serum biomarkers of inflammation for diagnosis of prostate cancer in patients with nonspecific elevations of serum prostate specific antigen levels. Transl Cancer Res 8(1): 273-278, 2019. DOI: 10.21037/ tcr.2019.01.31

22 Ren HY, Sun LL, Li HY and Ye ZM: Prognostic significance of serum alkaline phosphatase level in osteosarcoma: a metaanalysis of published data. Biomed Res Int 2015: 160835, 2015. PMID: 26618165. DOI: 10.1155/2015/160835

$23 \mathrm{Li} \mathrm{D}, \mathrm{Lv} \mathrm{H}$, Hao X, Hu B and Song Y: Prognostic value of serum alkaline phosphatase in the survival of prostate cancer: evidence from a meta-analysis. Cancer Manag Res 10: 31253139, 2018. PMID: 30214305. DOI: 10.2147/CMAR.S174237

24 Xu XS, Ryan CJ, Stuyckens K, Smith MR, Saad F, Griffin TW, Park YC, Yu MK, Vermeulen A, Poggesi I and Nandy P: Correlation between prostate-specific antigen kinetics and overall survival in abiraterone acetate-treated castration-resistant prostate cancer patients. Clin Cancer Res 21(14): 3170-3177, 2015. PMID: 25829400. DOI: 10.1158/1078-0432.CCR-14-1549

25 Scher HI, Halabi S, Tannock I, Morris M, Sternberg CN, Carducci MA, Eisenberger MA, Higano C, Bubley GJ, Dreicer R, Petrylak D, Kantoff P, Basch E, Kelly WK, Figg WD, Small EJ, Beer TM, Wilding G, Martin A, Hussain M and Prostate Cancer Clinical Trials Working Group: Design and end points of clinical trials for patients with progressive prostate cancer and castrate levels of testosterone: recommendations of the Prostate Cancer Clinical Trials Working Group. J Clin Oncol 26(7): 11481159, 2008. PMID: 18309951. DOI: 10.1200/JCO.2007.12.4487

26 Rescigno P, Lorente D, Bianchini D, Ferraldeschi R, Kolinsky MP, Sideris S, Zafeiriou Z, Sumanasuriya S, Smith AD, Mehra N, Jayaram A, Perez-Lopez R, Mateo J, Parker C, Dearnaley DP, Tunariu N, Reid A, Attard G and de Bono JS: Prostate-specific antigen decline after 4 weeks of treatment with abiraterone acetate and overall survival in patients with metastatic castration-resistant prostate cancer. Eur Urol 70(5): 724-731, 2016. PMID: 26965561. DOI: 10.1016/j.eururo.2016.02.055

27 Armstrong AJ, Saad F, Phung, Dmuchowski C, Shore ND, Fizazi $\mathrm{K}$, Hirmand $\mathrm{M}$, Forer $\mathrm{D}$, Scher $\mathrm{HI}$ and Bono J: Clinical outcomes and survival surrogacy studies of prostate-specific antigen declines following enzalutamide in men with metastatic castration-resistant prostate cancer previously treated with docetaxel. Cancer 123(12): 2303-2311, 2017. PMID: 28171710. DOI: $10.1002 /$ cncr.30587 